\title{
CONTRIBUTO DAS TECNOLOGIAS DIGITAIS PARA O DESENVOLVIMENTO DE COMPETÊNCIAS DO SÉCULO XXI EM UMA AULA INVERTIDA
}

Adelina Silva

\section{RESUMO}

O objetivo deste artigo é apresentar uma reflexão sobre a forma como as tecnologias digitais contribuem para o desenvolvimento das competências para o aluno do século XXI, relacionando-as com a produção de conhecimento na escola, por meio da implementação de uma prática pedagógica, na modalidade de aula invertida. Partindo do pressuposto que os alunos estão enquadrados no conceito de "nativo digital", reflete-se sobre as competências, nos vários domínios, que se espera que o aluno atinja, detenha e alcance, na sala de aula, com recurso a tecnologias digitais e a ferramentas da Web 2.0. Para cumprir esse objetivo e o desafio educativo de uma escola em mudança, serão apresentadas 3 ferramentas aplicadas em sala de aula: uma plataforma educativa de partilha de conteúdo (Edmodo), um jogo (kahoot) e uma plataforma de avaliação de conhecimentos (Socrative).

Palavras-chave: Competências século XXI. Aula invertida. Tecnologias digitais.

Web 2.0.

\section{ABSTRACT}

The purpose of this article is to produce a reflection on how digital technologies contribute to the development of skills of the $21^{\text {st }}$ century student, linking them to knowledge production in school, through the implementation of a pedagogical practice in the classroom known as flipped classroom. Assuming that students are "digital natives", this article focus on the skills in various areas that students are expected to accomplish and hold as well as how to achieve them in a classroom, using digital technologies and Web 2.0 tools. To achieve this goal and the educational challenge of an ever changing school, three tools were applied in the classroom: an educational platform for sharing content (Edmodo), a game (Kahoot) and a knowledge evaluation platform (Socrative).

Keywords : 21 st century skills. Flipped classroom. Digital technologies. Web 2.0

Investigadora

do Grupo de

Investigação

em Media e

Mediações

Culturais

(CEMRI),

Universidade

Aberta, Portugal,

e do Grupo

de Estudos e

Pesquisa em

Tecnologia

Educacional

e Educação

a Distância

(GETED) da

Universidade

Católica Dom

Bosco (UCDB),

Brasil. E-mail:

silvadelina@

gmail.com 


\section{INTRODUÇÃO}

A forma como experienciamos a aprendizagem está em mudança. Seymour Papert aventou que os computadores se tornariam o instrumento-chave para a educação. A previsão de Papert tornou-se uma realidade. A evolução tecnológica e a sua implementação na sala de aula tem um forte impacto na educação. Os ambientes de aprendizagem tradicionais dizem muito pouco aos alunos, que se dizem da geração millenium. Cada vez mais, aos alunos proporciona-se uma forma individualizada e personalizada de ensino que pode ser acessado em qualquer lugar e em qualquer momento. Essa geração de alunos, que veem a tecnologia como um recurso rotineiro, enquadra-se no que Prensky chamou de "nativos digitais". O impacto da tecnologia na educação deixou de ser novo e excitante; pelo contrário, tornou-se simplesmente uma necessidade.

A tecnologia, e em particular a Internet, as plataformas da Web 2.0, os dispositivos móveis, os computadores e as realidades virtuais, tornaram-se um aferidor do funcionamento da sociedade. Graças às iniciativas BYOD (Bring Your Own Device) ou BYOT (Bring Your Own Technology), e à computação em nuvem, assistimos a uma mudança radical de paradigma educativo. Além disso, como nativos digitais, os alunos sentem-se confortáveis com esta tecnologia, pelo que os programas de desenvolvimento necessários para a sua implementação só serão exigidos àqueles que não estão familiarizados com a tecnologia digital e com as ferramentas $\mathrm{Web} 2.0$.

Este artigo irá abordar a forma como a era digital está impulsionar as práticas educativas para uma mudança, de acordo com as exigências das competências que se exigem para o século XXI, nas várias vertentes.

As ferramentas Web 2.0 apresentadas neste artigo são de fácil aplicabilidade e utilização, quer por parte de professores quer de alunos. É importante que, no ensino de competências exigidas aos alunos de hoje, essa mudança de paradigma se realize ao nível do processo de aprendizagem, envolvendo o próprio aluno, de uma forma mais motivadora e responsável, tornando-o autor/produtor de conteúdo. Para se concretizar esse objetivo há que repensar as metodologias pedagógicas em sala de aula, aliando-as às tecnologias digitais - flipped classroom. 


\section{DAS COMPETÊNCIAS DO SÉCULO XXI À AULA INVERTIDA}

Vivemos num mundo orientado pela mudança, em grande parte, imposta pela inovação tecnológica. $\mathrm{Na}$ escola de hoje, não aderir às mais recentes tecnologias educacionais está fora de questão e, os que não o fazem correm o risco de não acompanhar os tempos modernos. Nem todos concordam que as tecnologias per si sejam de obrigatória integração na sala de aula, sendo certo que não é o uso da tecnologia que conduz a uma mudança significativa na aprendizagem do aluno.

O sucesso educativo alcança-se quando se proporciona aos alunos um conjunto de competências que os prepara para os desafios da sociedade, nomeadamente, os da era digital.

O que se exige aos profissionais da educação vai muito mais além do que um perito tecnológico, um pedagogo ou um especialista em conteúdo. Hoje, os professores têm de apreender quais as competências que se exigem no século XXI e desse modo poder transmiti-las aos seus alunos. As boas práticas educativas compreendem uma interação dinâmica assente em três pilares: conteúdo, pedagogia e tecnologia, vulgarmente chamado de TPACK.

John Dewey, no livro Escola e Sociedade, escrevia que o conhecimento não é mais um sólido imóvel, pois o conhecimento tornou-se "liquefeito" ou "líquido", na perspectiva de Zygmunt Bauman, à medida que se move ativamente no sentido das correntes da própria sociedade. Esta ideia poder-se-ia aplicar ao potencial educativo da Web 2.0, às tecnologias móveis ou às novas ferramentas educativas que foi surgindo a uma velocidade desenfreada. Contudo, esse pensamento foi registado por volta de 1900, há um século atrás, muito antes da internet ter sido concebida, muito antes dos primeiros computadores e dos dispositivos que temos hoje à nossa disposição. A própria noção de movimento e circulação de informação à velocidade da luz, a uma escala planetária, na qual textos, imagens e sons são manipulados e digitalizados, é o culminar de conceito de um educador visionário.

Dentro dessa conceção do conhecimento liquefeito ou líquido, não podemos ignorar as ferramentas que nos são proporcionadas pela Web 2.0, quer para o professor quer para o aluno, que impulsionam e estimulam a mudança de práticas pedagógicas dentro e fora da sala de aula. Nos tempos que vivemos, o que temos de constante é a mudança. Assim, a flexibilidade, quer no uso das tecnologias ou no nível da pedagogia, é um imperativo da escola de hoje. 
Contudo, essa flexibilidade pressupõe um conhecimento da aplicabilidade pedagógica dessas ferramentas, pois só desse modo os professores estarão prontos para os desafios educativos que se afiguram. Assistimos, muitas vezes, as escolas de hoje que não ensinam as competências necessárias e exigidas pela sociedade de hoje, porque estão reféns de um sistema educativo do século XX. Por exemplo, se analisarmos a própria disposição das salas, verificamos que existem diferenças mínimas nas salas de aula de hoje em comparação com salas de aula do século anterior. Continua-se a solicitar e a exigir aos alunos que dominem conhecimentos básicos, factuais, na sala de aula, sendo avaliados por apenas esse conhecimento. Certo é que tem havido um crescente movimento para incutir as competências do século XXI no sistema de ensino. Alguns opinam que isso não passa de uma tendência passageira, impulsionada por diversas organizações. A verdade é que teve o mérito de chamar a atenção de todos os envolvidos no processo de ensinoaprendizagem para a necessidade de formação para uma escola que se diz na era digital.

As competências do século XXI estão estruturadas em 4 pilares. O primeiro assenta na forma de pensar e abrange a criatividade, a inovação, o pensamento crítico, a resolução de problemas e a capacidade de decisão - é o aprender a aprender -. O segundo consiste na forma de trabalhar, ou seja, nas relações interpessoais que se estabelecem, para as quais a colaboração e o trabalho em equipe contribuem com bastante destaque. O terceiro, prende-se com as ferramentas para trabalhar, isto é, engloba a literacia para a informação, as tecnologias da comunicação e os media. Finalmente, o viver no mundo, aponta para a responsabilidade pessoal e social, a cidadania local e global, a vida e a carreira. Exige-se que os indivíduos compreendam o seu lugar no mundo e a forma em que se relacionam (comunicação, partilha, colaboração), com criatividade e inovação (capacidade de aplicar com êxito os conhecimentos adquiridos no desenvolvimento de novas soluções para os problemas e de enfrentar situações de desafio, "pensar fora da caixa").

Os espaços de aprendizagem (quer na escola, quer na Web 2.0, como extensão da escola enquanto espaço físico) são locais propícios para explorar, utilizar e aplicar as competências educacionais para este século, de uma forma eficaz e inovadora, preparando os alunos não só para a aprendizagem na escola, mas também para a aprendizagem ao longo da vida.

Exigem-se dos professores e dos alunos competências técnicas para reforçar as capacidades para, por si próprios, aprenderem sobre o mundo, por meio de uma 
pesquisa, por exemplo. Exigem-se, também, competências de pensamento crítico e comparativo, incluindo a capacidade de pensar criticamente e integrar conhecimento, mais do que aceitar conhecimento de forma não crítica.

Essa capacidade de avaliar e analisar criticamente informação é crucial, mas não é a única. A produção de informação e conteúdo utilizando ferramentas multimodais (áudio, vídeo e texto), a publicação do conteúdo e o trabalho em rede com outras pessoas online é uma imposição nos dias hoje.

As competências requeridas aos estudantes de hoje são, muitas vezes, referidos como os C's de mudança - criatividade, pensamento crítico, colaboração, comunicação, contexto cultural e conectividade. A comunicação e a colaboração são a capacidade dos indivíduos para efetivamente usar ferramentas digitais para discutir e resolver problemas que surjam, com criatividade e inovação. A distância ou tempo, ou ambos, podem separar os envolvidos, mas nunca deve ser um empecilho para o sucesso do projeto. O contexto cultural aponta para a capacidade de usar ferramentas digitais para encontrar informação, filtrar recursos disponíveis e avaliar a validade dos dados apresentados, além de envolver a capacidade de escolher a ferramenta mais eficaz para concluir o projeto e encontrar um nível de conforto pessoal para trabalhar com ferramentas digitais. O pensamento crítico e a resolução de problemas são conceitos transversais a todos os aspetos da vida, trabalho e escola, e podemos centrá-lo no ato de ensinar as pessoas a tomar decisões bem informadas e avaliar o efeito que ações pessoais terão sobre os outros.

A mudança é exigida tanto para professores como para alunos. Trata-se de repensar não só no que é ensinado, mas como é ensinado, tornando necessário preparar os nossos atuais professores e futuro promissor os professores com um completo conjunto de conhecimentos e de recursos que lhes permitam implementar as competências na sala de aula, de maneira relevante e significativa, pois é certo que não se altera a forma como os alunos aprendem até que os professores estejam preparados para ensinar de novas formas. Seria irracional pensar que os alunos adquirissem as competências e os conhecimentos necessários para o sucesso, se essas fossem ensinadas por professores pouco preparados.

O professor do século XXI é, sobretudo, um indivíduo que se adapta às mudanças. Deve ser capaz de adaptar o currículo e os requisitos para ensinar de forma imaginativa. Devem ser capazes de adaptar software e hardware em ferramentas utilizáveis por uma variedade de grupos de idade e habilidades. Deve ser capaz de se adaptar a uma experiência de ensino dinâmico e interativo. Deve aplicar 
diferentes estilos de aprendizagem, adaptando o estilo de ensino a diferentes modos de aprendizagem.

O ensino e a aprendizagem do século XXI são caracterizados pelas competências e ferramentas disponíveis para se tornar o produtor e criador, e (re)fazer conteúdo.

As ações de formação direcionadas aos docentes devem ter um objetivo trabalhar com os alunos. A questão é saber o quão preparados estão para trabalhar com os alunos de hoje, com as necessidades em constante mutação. Falamos de nativos da era digital, com experiência tecnológica e suficiente à vontade para se movimentarem num mundo onde as respostas estão disponíveis ao alcance de seus dedos e a tecnologia é uma ferramenta tanto como um brinquedo.

Vivem e aprendem no mundo da Web 2.0, o que torna aos professores as expectativas tão díspares como excitantes ou assustadoras. Não basta deter conhecimento científico e competências pedagógicas. Há que, acima de tudo, ter competências técnicas e tecnológicas, sobretudo ao nível das ferramentas Web 2.0, e a sua aplicação pedagógica, na sua prática letiva.

Nos últimos 200 anos, o conteúdo educativo e a forma como foi desenvolvido na sala de aula sofreu poucas alterações. Katie Ash (2012) designa esse período de “educação industrializada”, na qual os alunos são obrigados a memorizar factos e simplesmente aplicá-los nos campos de interesse, numa lógica muito idêntica à dos trabalhadores durante a Revolução Industrial. Porém, já nessa altura, os professores de Inglês e de Artes exigiam aos alunos que lessem em casa e viessem para a aula preparados para discutir e sintetizar a sua aprendizagem, no que hoje se assemelha à metodologia no modelo de aprendizagem de aula invertida - flipped classroom.

Dois séculos após a Revolução Industrial, o ambiente de trabalho mudou. A internet e os computadores móveis tornaram-se onipresentes e o acesso à informação é prolixo. O mundo que existe fora das escolas está a mudar, mas a tradicional sala de aula não. Os alunos ainda são obrigados a demonstrar compreensão através da memorização, embora a acessibilidade à informação esteja à disposição. Testes padronizados continua a testar o conhecimento memorizado que, muitas vezes, não reflete o nível de compreensão dos conteúdos (ROEHL; REDDY; SHANNON, 2013).

Conquistas recentes de tecnologia, alteraram e ampliaram o conceito de aprendizagem para os professores. Por exemplo, o uso de software de vídeo na gravação de uma palestra ou de uma aula, e a sua distribuição em sites de 
alojamento, torna-a onipresente e acessível, libertando tempo de aula para a interação face-a-face com os alunos.

Desde 2007, o conceito de aprendizagem aula invertida - flipped classroom tem começado a enraizar na escola, em diversos níveis de escolaridade. Tudo começou quando dois professores de Ciências da Woodland Park High School, no Colorado, Estados Unidos da América, Jonathan Bergmann e Sams Aaron, decidiram usar software de captura de imagem e som para gravar aulas introdutórias e solicitavam que os alunos assistissem a esses vídeos como trabalho de casa. Os alunos utilizavam, então, o tempo de aula para atividades mais construtivas.

Embora o conceito de aula invertida já tivesse sido utilizado na educação antes de 2007, o objetivo era ensinar principalmente cursos online, via Internet. No entanto, no livro Flip your Classroom, Bergmann e Sams (2012) afirmam que a sua iniciativa foi um pouco diferente. Eles começaram fazendo os vídeos para que pudessem aumentar o tempo de contato despendido face-a-face com cada aluno durante a aula. Isso permitiu uma avaliação mais formativa, uma aula mais orientada e uma aprendizagem diferenciada.

Sal Khan começou oficialmente a Kahn Academy em 2008, fornecendo vídeos sobre conceitos matemáticos e de ciência, passo a passo. A ideia de criar esses vídeos surgiu das sessões de tutoria online com a sua sobrinha. Khan utilizava os vídeos para produzir o máximo de conteúdo. De imediato descobriu que, ao gravar os seus vídeos, a sua sobrinha podia parar, retroceder ou visioná-los múltiplas vezes se necessário, ao invés de uma sala de aula tradicional, o que o levou a repensar a educação formal. Com o apoio financeiro de vários mecenas, Khan criou a Khan Academy, que se tornou o sítio em que mais aulas funcionaram no mesmo espaço.

Nos últimos anos, o conceito de flipped learning tem tido uma maior divulgação no campo educativo, em que a ênfase é colocada sobre o processo de aprendizagem. Assiste-se a uma mudança pedagógica, os professores começam a olhar para o conceito de aprendizagem invertida como uma possível mudança do formato tradicional para um modelo que se assemelhe mais a um ambiente no qual os alunos são familiarizados fora da sala de aula.

A implementação de uma nova metodologia levanta sempre algumas questões, nomeadamente a da sua eficácia.

Há quem o avalie pela taxa de sucesso na avaliação e na prestação escolar do aluno nos testes e questione se uma mudança pedagógica baseada em vídeos oferece mais e melhor conteúdo educativo. Se o velho método de aulas expositivas, lápis e 
papel, quadro e giz são eficazes, questiona-se o porquê da utilização de outros métodos que exigem muitas horas de preparação e equipamento. No entanto, a maioria dos estudos não se centra apenas nas classificações e na prestação do aluno (DAVIES; DEAL; BALL, 2013; ENFIELD, 2013; GAUGHAN, 2014; LAGE; PLATT; TREGLIA, 2000; MURPHREE, 2014; STRAYER, 2012; WILLEY; GARDNER, 2013). Muitos desses autores apresentam e incluem dados qualitativos que exploraram as percepções dos alunos do novo ambiente de aprendizagem.

Nem todos os professores que aplicam a metodologia da aula invertida têm sucesso. Alguns que estão tentando inverter a aula têm relatado que por vezes a sua implementação é difícil. Isso pode dever-se a duas razões (BERGMANN; SAMS, 2012):

a) o ambiente da aula não está adequadamente alinhado com o conceito de aula invertida.

b) o conteúdo é "empurrado" para fora do horário da aula e pressupõe que os alunos o tenham estudado e, quando não o fazem, os professores têm dificuldade em utilizar plenamente a aula programada para uma aprendizagem significativa.

Segundo Bergmann e Sams (2012), o ponto fraco da abordagem tradicional é a de que nem todos os alunos vêm para a aula preparados para aprender. A utilização dessa metodologia na sala de aula e as mudanças que se impõem à escola a par da exigência das competências educativas para o século XXI colocam as seguintes questões a todos os professores:

a) que mais valias existem num ambiente de aprendizagem invertido versus ambiente tradicional?

b) quais os efeitos do ambiente de aula invertida no envolvimento do aluno?

c) quais os efeitos de uma aula invertida na aprendizagem dos alunos?

\section{UMA EXPERIÊNCIA DE AULA INVERTIDA}

A aula invertida - flipped classroom - assenta fundamentalmente em tecnologia e, particularmente, nas ferramentas da Web 2.0. Mas, o que é que a Web 2.0 tem a oferecer aos professores? As mudanças que se têm vivenciado na escola 
têm reforçado uma série de práticas que evidenciam o potencial de aprendizagem da web.

A Web 2.0 possibilita e facilita a socialização, a colaboração, a criatividade, a autenticidade e a partilha. Com a socialização os alunos podem desenvolver a linguagem e as competências comunicacionais, ao mesmo tempo que aprendem a construir redes e desenvolver competências relacionais. Fortalecem o espírito de equipe, pois trabalhando em conjunto com os outros constroem e compartilham conhecimento, criam conteúdos e produtos numa ampla gama de ferramentas e de mídia, para uma audiência real, tornando-os produtores/autores. As tarefas e as atividades que desenvolvem e os indivíduos com quem interagem são um fator motivacional para o bom desempenho educativo. Finalmente, mas não menos importante, existe a possibilidade de compartilhar o que criaram e aprender uns com os outros em rede.

Irei proceder à apresentação de uma prática de aula invertida, com alunos de $8^{\circ}$ ano, do ensino básico, com idades compreendidas entre os 12 e os 14 anos. A turma é constituída por 20 alunos, 11 do sexo feminino e 9 do sexo masculino. Desses, 2 alunos estão diagnosticados como sendo alunos com necessidades educativas especiais, o que requerem uma atenção mais individualizada e personalizada em sala de aula. A turma é composta por 5 alunos que estão a repetir o ano pela segunda vez.

No artigo Da aula convencional para a aula invertida - ferramentas digitais para a aula de hoje, Silva (2015) apresenta 16 ferramentas que poderão ser aplicadas na sala de aula. Nessa experiência, utilizei três ferramentas da Web 2.0: kahoot, Edmodo e Socrative.

\subsection{Ferramenta Edmodo}

Logo no início do ano letivo, foi apresentada à turma a plataforma Edmodo (www.Edmodo.com), na qual foi criada a sala da turma e os alunos foram inscritos. As principais características dessa plataforma assentam nos princípios da cooperação e da colaboração e permitem, entre diversas operações, efetuar algumas das seguintes:

a) os professores e os alunos podem colaborar num ambiente seguro e fechado; 
b) o sistema de mensagens permite a comunicação segura e aberta, com monitorização e controle por parte do professor;

c) a interação dos alunos é fácil de monitorar;

d) os professores podem definir trabalhos num prazo pré-determinado que serão submetidos pelos alunos e fichas de avaliação que serão avaliadas automaticamente;

e) os professores e outros membros da escola podem criar grupos para alargar as comunidades por área temática;

f) os professores e os alunos podem armazenar e partilhar documentos e ficheiros de vários formatos num ambiente baseado em computação na nuvem - cloud computing;

g) os professores podem manter uma biblioteca de conteúdos com a possibilidade de partilha com outros membros;

h) o sistema de partilha permite aos professores a partilha de conteúdos por unidades curriculares, grupos de alunos ou membros individuais;

i) o encarregado de educação ou a família pode ter uma conta de controle parental;

j) a interface é simples e intuitiva - sem necessidade de conhecimentos prévios;

k) serviço gratuito e livre de publicidade.

A utilização do Edmodo começa com a criação de um perfil. A conta de professor no Edmodo cria-se na página principal na hiperligação "I'm a Teacher". Antes de um aluno se registar no Edmodo, necessita de um código de 6 dígitos que é fornecido pelo professor. Esse tipo de registo não carece de uma conta de e-mail. No entanto, é recomendável, que o aluno efetue a sua inscrição, sugerindo a sua conta de correio eletrónico, para assim receber as notificações no futuro. Existe, também, a possibilidade de controlo parental. As contas de controlo parental são uma excelente forma de manter os pais, ou encarregados de educação, informados sobre as atividades da sala de aula, das tarefas, das notas e dos eventos escolares. Neste tipo de conta, o processo de registo é semelhante ao do registo do aluno, com uma segurança adicional - cada encarregado de educação terá de se registar com um código correspondente ao seu educando. Dessa forma, garante-se uma interação segura entre pais e professor. 


\section{Figura 1 - Plataforma Edmodo}

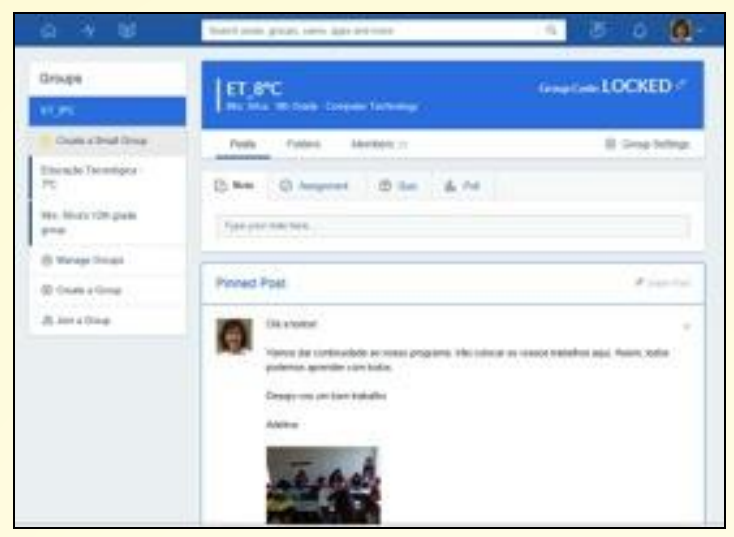

A plataforma tem uma interface muito parecida com uma rede social. $\mathrm{Na}$ página principal vão surgindo as notificações, do que vai sendo partilhado pelos seus membros.

Figura 2 - Postagens do grupo

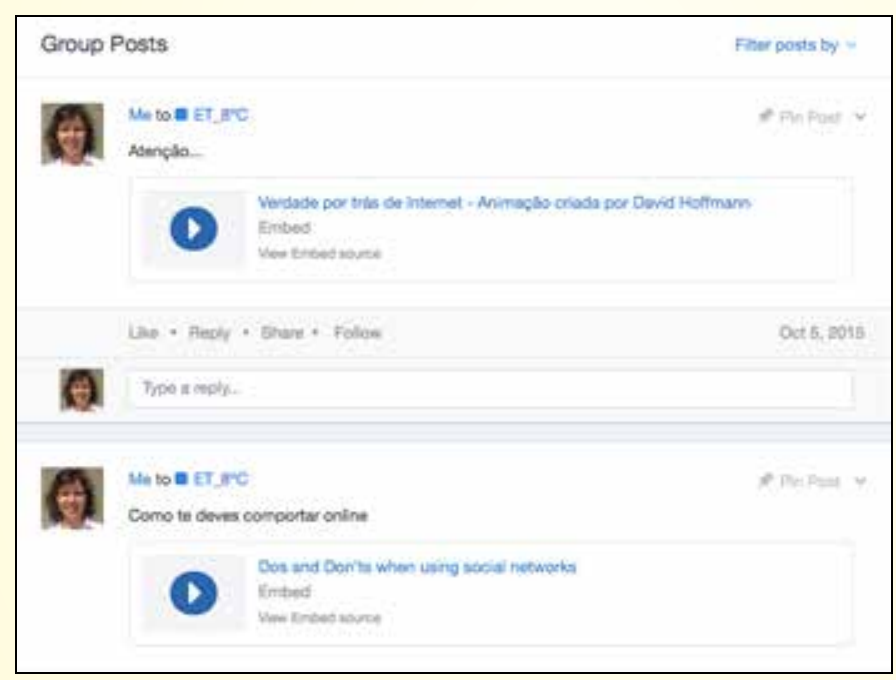

Uma vantagem é a constituição de pequenos grupos de trabalho, dentro da mesma turma.

Para promover a participação e o engajamento de todos há a hipótese de atribuir medalhas aos alunos, quer pelo índice de participação, de desempenho ou de ajuda aos colegas, entre outros. Algumas estão predefinidas, outras poderão ser criadas pelo professor. 
Figura 3 - Medalhas

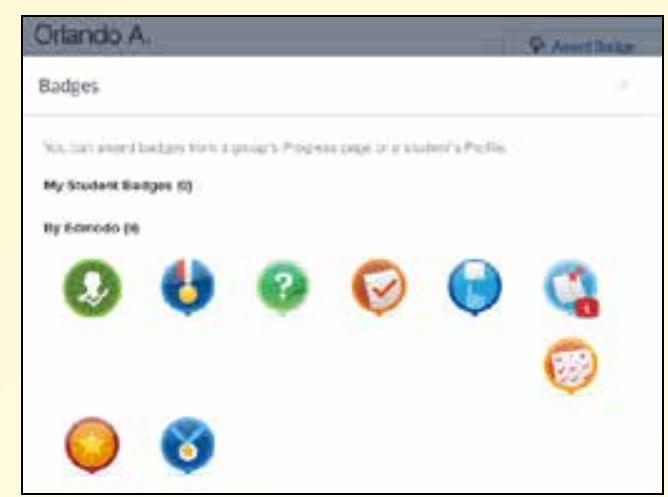

É possível a programação de tarefas e a consequente entrega do trabalho pela plataforma.

Figura 4 - Calendarização de entrega de trabalhos

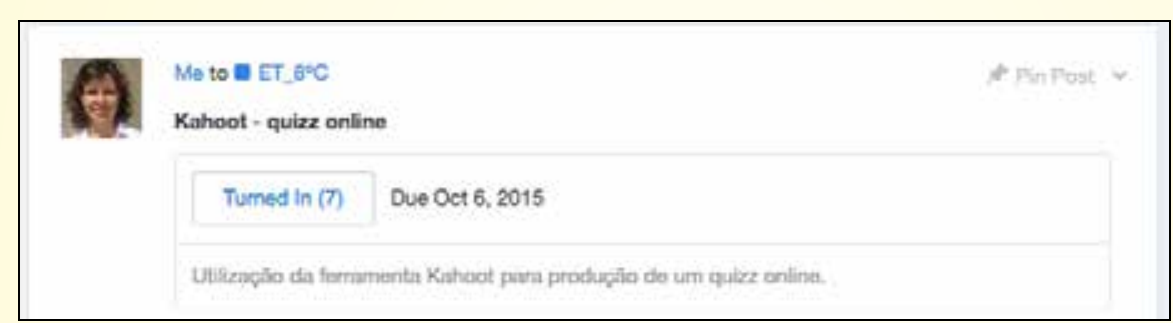

Uma vez entregue o trabalho, ele poderá ser avaliado e comentado pelo professor, que lhe atribui uma classificação numa escala definida por ele. Os encarregados de educação têm acesso ao trabalho, à classificação quantitativa e qualitativa, bem como do prazo das datas de entrega do trabalho.

\section{Figura 5 - Trabalhos entregues ou em falta}

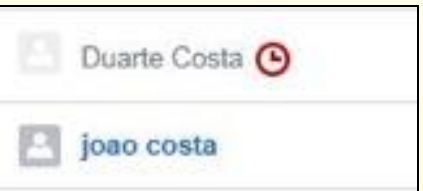

Os trabalhos podem ser consultados pelo colegas da turma. Dessa forma, todos aprendem com todos, e o processo de avaliação é mais transparente. 
Figura 6 - Avaliação dos trabalhos

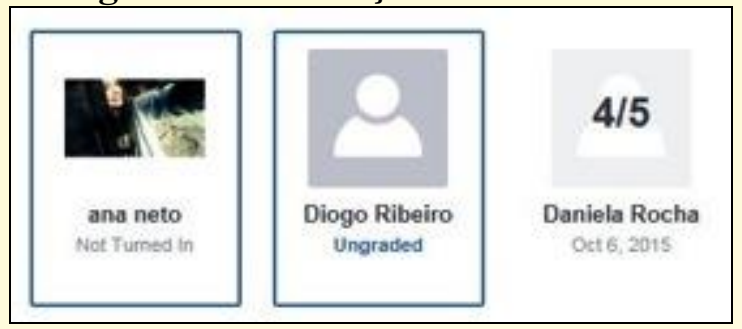

A plataforma permite a realização de testes de múltipla escolha, de verdadeiro e falso e de preenchimento de espaços. A partir do momento que o teste é enviado para um grupo ou para alguns membros, os alunos podem selecionar a opção "Take Quiz", localizada ao lado da data limite de realização, para iniciar a resolução do teste. Se as questões forem do tipo múltipla escolha, verdadeiro ou falso ou preenchimento de espaços, as respostas estarão já marcadas com correto ou incorreto, com base nas indicações dadas na especificação inicial do teste. Para mostrar os resultados aos alunos basta ativar a opção "Show results to quiz takers".

Também é possível a avaliação de um teste sem correção automática. No final da correção basta ativar a opção "Show results to quiz takers", que permitirá ao aluno verificar a pontuação do seu teste. Se for conveniente, é possivel adicionar a classificação do aluno ao Gradebook - o sistema de avaliação da turma do Edmodo.

\subsection{Ferramenta Kahoot}

A ferramenta Kahoot (www.Kahoot.it) é uma plataforma que permite em tempo real a aprendizagem baseada num jogo de multijogadores. Trata-se de uma abordagem inclusiva para a aprendizagem, usando qualquer dispositivo com acesso à Internet. Permite a criação de um jogo, com uma bateria de perguntas sobre um tópico específico, com vídeos incorporados, aparência, gráficos e imagens, com base em conteúdo educacional e o seu consequente compartilhamento. As perguntas podem ser colocadas sob a forma de questionário, discussão ou sondagem, criados quer pelo professor quer pelos próprios alunos. 


\section{Figura 7 - Início do jogo em Kahoot}

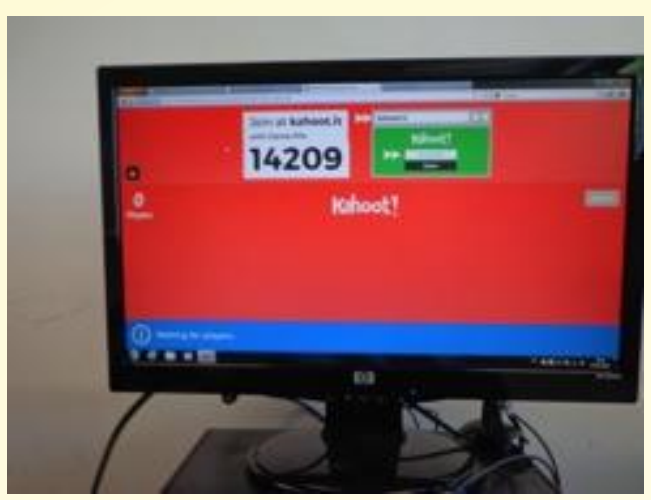

Essa ferramenta é um excelente exemplo de aprendizagem, baseada em jogos e aplicando o modelo de "sala de aula invertida", para gerar uma experiência que seja envolvente e emocionante para os alunos.

Figura 8 - Utilização de celular na sala de aula

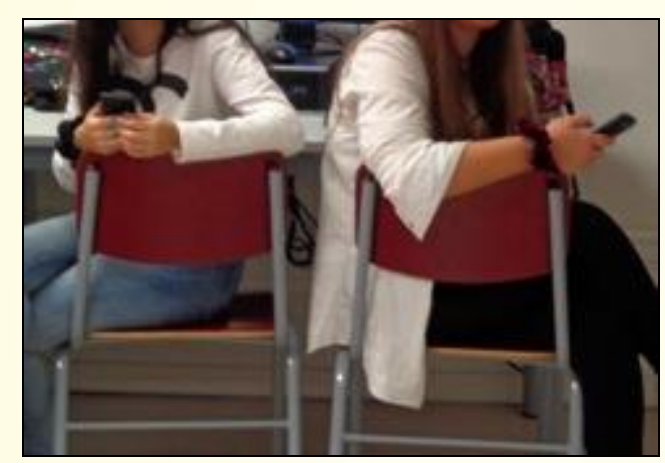

Cada aluno pode aceder e participar no jogo por meio do seu próprio dispositivo móvel, e promove uma atmosfera competitiva amigável. Por exemplo, os alunos sabem individualmente, em cada dispositivo, se cada pergunta respondida por si está certa ou errada. Contudo, na parte da frente da turma, normalmente exibido em um projetor ou quadro interativo, eles podem ver os resultados globais da classe em gráfico, sem nomear quem errou. A aprendizagem torna-se divertida, introduzindo a possibilidade de "ganhar", o que envolve significativamente os estudantes e encoraja o comportamento positivo e o pensamento crítico. 
Figura 9 - Informação individual da prestação de cada jogador

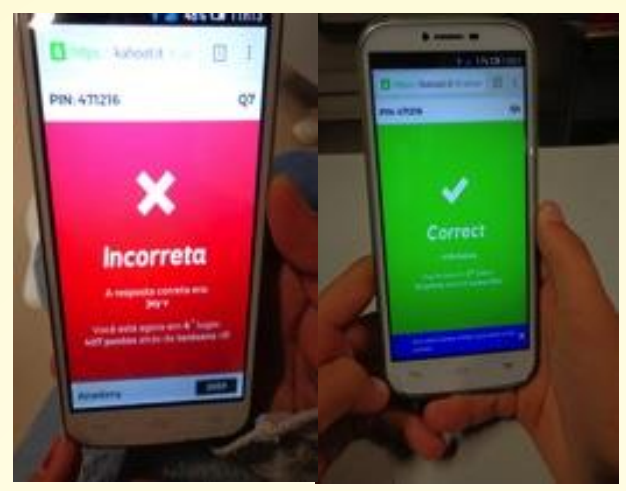

Outro aspeto extremamente exclusivo para a pedagogia do Kahoot é que os alunos são incentivados a criar, mais tarde, os seus próprios testes, a partir dos quais o professor pode escolher o melhor para aplicar na aula, como teste formativo, por exemplo. Essa possibilidade é única e inovadora porque fomenta um maior envolvimento a nível conceitual com o tópico em questão. Devido à natureza dos questionários de escolha múltipla, ao criar o seu próprio questionário, os alunos são estimulados a considerar possíveis respostas erradas, o que exige um maior envolvimento intelectual e compreensão da matéria em estudo, fortalecendo o seu espírito crítico. As análises fornecidas pelo Kahoot, num ficheiro em formato Excel, para pais, alunos e professores, permitem uma avaliação mais precisa do desempenho e um melhor acompanhamento de progresso de aprendizagem do aluno, bem como permitem, no curto prazo, um "instantâneo" do nível de conhecimentos do educando sobre uma determinada matéria.

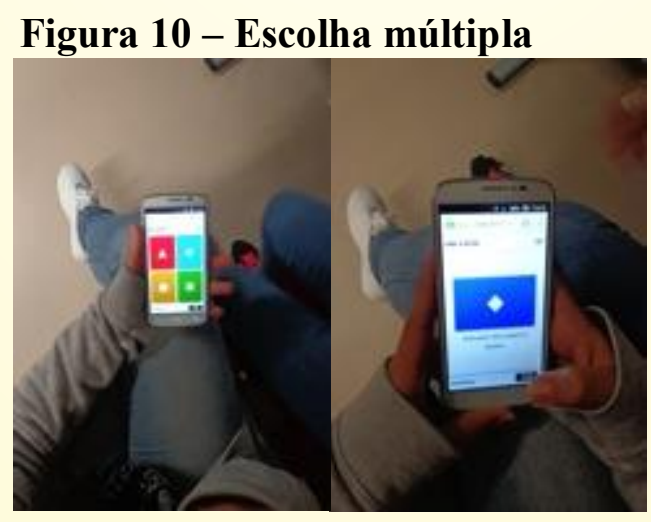

Na primeira aula, foi aplicado um teste diagnóstico sobre a matéria a abordar na disciplina, usando a ferramenta Kahoot. Com base nos resultados obtidos, foi produzido um relatório, que reportou as lacunas individuais de cada aluno. Esse 
relatório serviu de base para a planificação anual da disciplina, de acordo com as dificuldades detetadas.

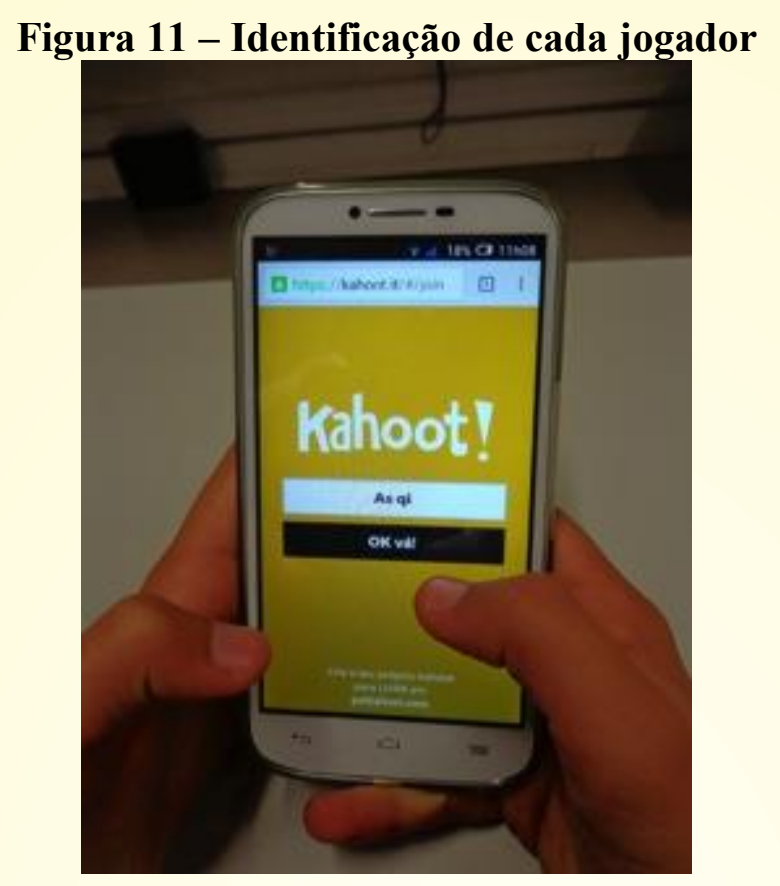

Numa outra aula, foi apresentada a ferramenta e solicitou-se aos alunos que em pares apresentassem um questionário sobre determinada matéria. Cada um dos grupos apresentou, numa outra aula ainda, o trabalho produzido aos colegas, que procederam à realização individualizada de cada um dos questionários.

Com o Kahoot, a aula inverteu-se de tal modo que permitiu aos alunos que se tornassem criadores/autores de conteúdo educacional.

\section{SOCRATIVE}

O Socrative (www.socrative.com) é uma ferramenta de avaliação baseada na web, que contém um sistema de sala de aula. Os alunos recebem um código para entrar na sala do professor para começar uma avaliação. O professor tem opção de escolha do tipo de prova que vai aplicar bem como o feedback a dar (ao ritmo do aluno ou ao ritmo do professor). 


\section{Figura 12 - Escolha da tipo de prova}

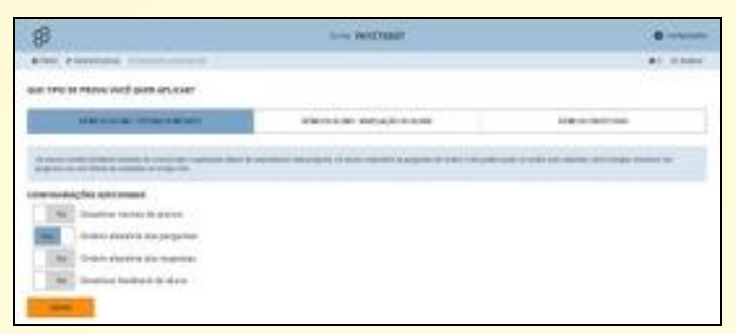

A entrada na plataforma acontece após a identificação do professor e do aluno, depois de se conhecer o código da sala.

Figura 13 - Identificação no Socrative

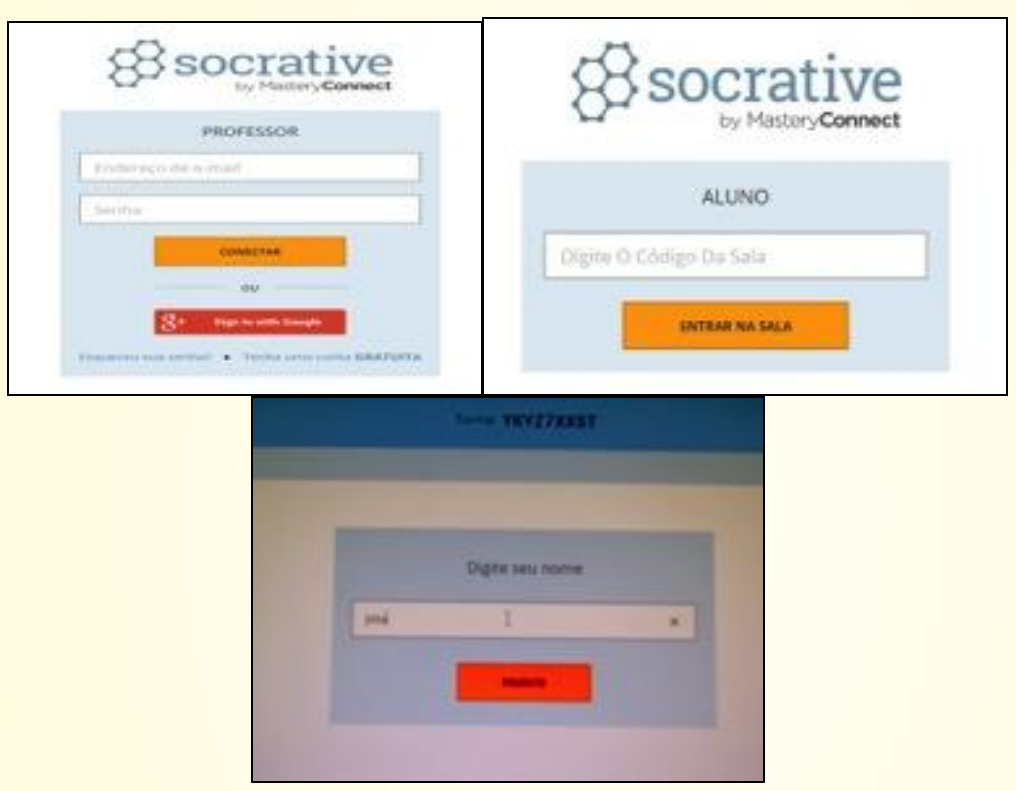

Após a entrada na sala da turma atribuída pelo código gerado, o aluno poderá escolher a modalidade de avaliação individual ou de grupo, de acordo com o estabelecido pelo professor.

No caso de ser de grupo, o aluno procede de seguida à escolha do grupo.

Figura 14 - Escolha da equipa

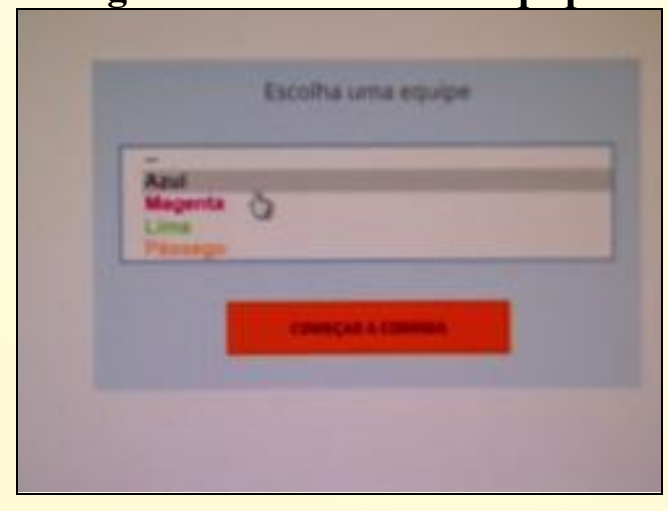


Dando início ao teste, a avaliação inclui feedback imediato, questões de resposta aberta ou de escolha múltipla, de acordo com o que o professor tiver construído.

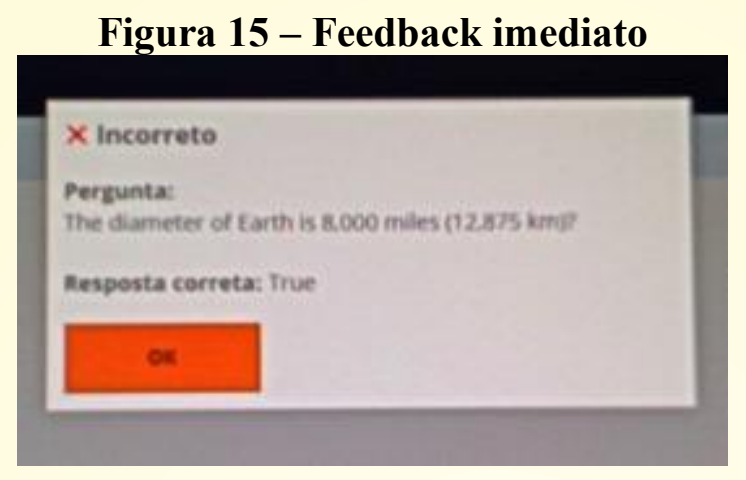

A atividade de grupo é apresentada sob a forma de uma corrida espacial, transformada num gráfico de resultados. O grupo que tiver mais respostas corretas é o que mais rápido percorre a pista.

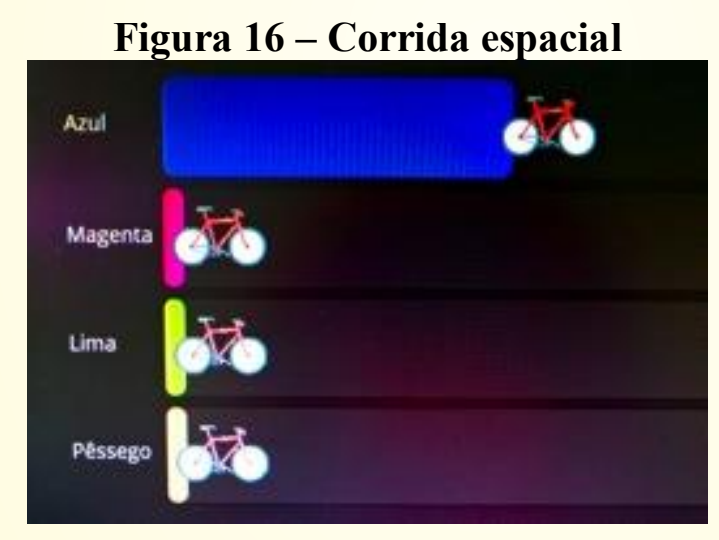

O professor usa as opções de resposta curta para obter feedback instantâneo sobre um objetivo de aprendizado. Por meio do uso desta ferramenta, o professor pode avaliar rapidamente o aluno ou o progresso classe inteira para determinar se eles estão prontos para passar para o próximo tópico. 


\section{Figura 17 - Avaliação final do professor}

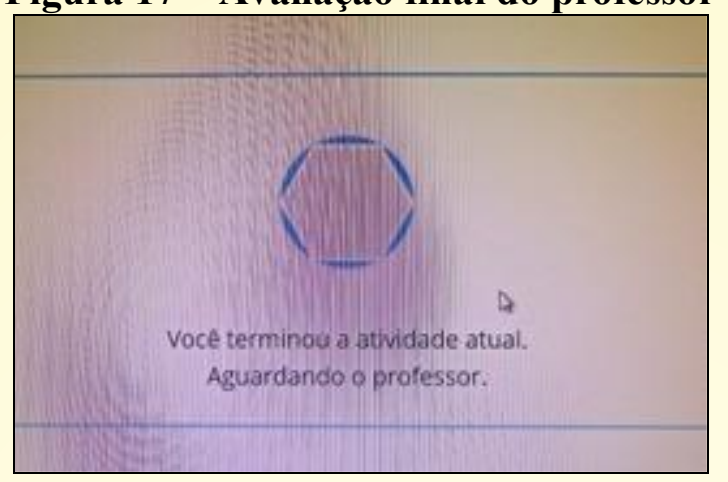

Cada sala Socrative, gratuita para professores e para alunos, tem capacidade para 50 alunos, em simultâneo, responderem a um questionário. Depois de um questionário estar concluído, pode ser gerado um relatório, que pode ser descarregado pelo professor.

Figura 18 - Produção de relatório de avaliação

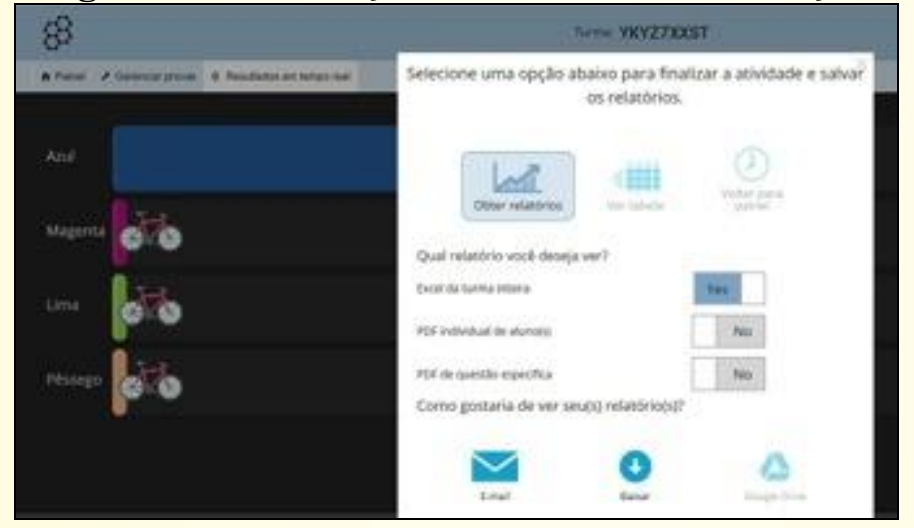

\section{CONCLUSÃO}

A implementação da tecnologia na escola não é um conceito inovador. A aplicação prática das tecnologias mencionadas neste artigo poderá, contudo, considerar-se inovadora. Essas tecnologias, articuladas, estão a provocar uma mudança no panorama educativo. Essa mudança inverte os papéis, colocando o aluno como aprendiz autonomo, em vez de um professor como único detentor do conhecimento. Ao professor é reservado o papel de orientador do processo educativo. Por consequência, impulsionados pelos avanços tecnológicos na educação, os alunos são incentivados a assumir um papel mais ativo na sua própria educação.

Utilizar a tecnologia tornou-se um imperativo na escola a exemplo do que acontece no mundo fora dela. A padronização da tecnologia na vida cotidiana tem 
sido em grande parte uma consequência da Internet. A Internet mudou, fundamentalmente, como a sociedade interage, comunica e apresenta a informação. Ela é a chave do desenvolvimento, da promoção e da implementação das tecnologias apresentadas neste artigo, na sala de aula, desenvolvendo uma das competências do século XXI - a literacia digital. Os cenários educacionais como a "aula invertida" também seriam impossíveis sem a Internet. Mas, sobretudo, permitem que a educação se projete para além da sala de aula, tornando-se uma extensão dessa. À medida que o mundo físico se funde cada vez mais com o mundo virtual, é imperativo que os alunos tenham acesso seguro e constante tanto à Internet como a um dispositivo de aprendizagem móvel. Só assim a educação poderá dizer-se individualizada, personalizada, interativa, flexível e acessível para todos os alunos.

As aulas da escola do século XXI assentam em práticas de gamificação, em plataformas Web 2.0, em aulas invertidas e na consequente análise de resultados de aprendizagem, munindo, assim, os professores de ferramentas facilitadoras de orientação, acompanhamento e apoio aos alunos de forma personalizada. Os alunos também serão capazes de utilizar esses dados para refletir sobre seus estilos de aprendizagem e sobre o seu progresso. O mundo virtual online pode oferecer aos alunos a capacidade de adquirir e aplicar conhecimentos, vivenciar experiências e receber feedback num ambiente que de outras formas, poderiam não ter acesso.

Este artigo centrou-se na tecnologia digital e no seu impacto no futuro da educação e nas competências exigidas para o século XXI. Este impacto, no entanto, não está reservado para o futuro; a tecnologia tem vindo a inovar as ideias e os métodos de ensino. Ser aluno nos dias de hoje, é viver um momento de mudança tecnológica emocionante; porém, a vantagem da tecnologia digital na sala de aula apresentada neste artigo é que ela permite a todos nós ser estudantes, em qualquer lugar, em qualquer idade e em qualquer momento. As práticas pedagógicas com recurso a tecnologia da $W e b 2.0$ expostas reinventam a sala de aula, a educação, e se implementadas corretamente, ajudar-nos-ão a tornar a educação globalmente inovadora, envolvente, personalizável e acessível. 


\section{REFERÊNCIAS}

ASH, K. Educators evaluate 'flipped classrooms': benefits and drawbacks seen in replacing lectures with on-demand video. Education Week, Bethesda, MD, v.32, n. 2, p. s6-8, 2012.

BERGMANN, J.; SAMS, A. Flip your classroom: reach every student in every class every day. Eugene, Or: International Society for Technology in Education, 2012.

BRUCE, C.; HUGHES, H.; SOMERVILLE, M. M. (2012). Supporting informed learners in the twenty- first century. Library Trends, Brisbane, v. 60, n. 3, p. 522545, 2012. Disponível em: <

http://muse.jhu.edu/journals/library_trends/v060/60.3.bruce.pdf $>$ Acesso em: 12 mar. 2014.

DAVIES, R. S.; DEAN, D. L.; BALL, N. Flipping the classroom and instructional technology integration in a college-level information systems spreadsheet course.

Educational Technology Research and Development, Washington, v. 6, n. 4, p. 563-580, 2013.

DEWEY, J. The school and society. Chicago: The University of Chicago Press, 1956.

ENFIELD, J. Looking at the impact of the flipped classroom model of instruction on undergraduate multimedia students at CSUN. Techtrends: linking research \& practice to improve learning, Washington, v. 57, n. 6, p. 14-27, 2013.

FINDLAY-THOMPSON, S.; MOMBOURQUETTE, P. Evaluation of a flipped classroom in an undergraduate business course. Business Education \&

Accreditation, Hilo, HI, v. 6, n. 1, p. 63-7, 2014. Disponível em: <

http://search.proquest.com/docview/1446438718?accountid=14691 >.

FULTON, K. P. Byron's flipped classrooms. Education digest, Ann Harbor, v. 79, n. 1, p. 22, 2013.

GAUGHAN, J. E. The flipped classroom in world history. History Teacher, Long Beach, Calif., v. 47, p. 2, p. 221-244, 2014.

KHAN ACADEMY. Salman Khan talk at TED 2011 (from ted.com). YouTube, 2011. Disponível em: $<$ https://www.youtube.com/watch?v=gM95HHI4gLk $>$.

LAGE, M. J.; PLATT, G. J.; TREGLIA, M. Inverting the classroom: a gateway to creating an inclusive learning environment. Journal of Economic Education, Washington, v. 31, n. 1, p. 30-43, 2000.

MASON, G.; SHUMAN, T.; COOK, K. Comparing the effectiveness of an inverted classroom to a traditional classroom in an upper-division engineering course. IEEE Transactions on Education, New York, v. 56, n. 4, p. 430-435, 2013. 
MURPHREE, D. S. "Writing wasn't really stressed, accurate historical analysis was stressed": student perceptions of in-class writing in the inverted, general education, University History Survey Course. History Teacher, Long Beach, Calif., v. 47, n. 2 , p. 209-219, 2014.

NIELSEN, L. Five reasons I'm not flipping over the flipped classroom. Technology \& Learning, Dayton, v. 32, n. 10, p. 46, 2012.

PEARSON EDUCATION. Flipped learning model dramatically improves pass rate for at- risk students. [case study]. United States of America: Pearson, c2013. Disponível em: < http://assets.pearsonschool.com/asset_mgr/current/201317/Clintondale_casestudy.pd $\mathrm{f}>$.

ROEHL, A.; REDDY, S.; SHANNON, G. The flipped classroom: an opportunity to engage Millennial students through active learning strategies. Journal of Family and Consumer Sciences, Alexandria, v. 2, n. 105, p. 44-49, 2013.

ROWE, M.; FRANTZ, J.; BOZALEK, V. Beyond knowledge and skills: the use of a Delphi study to develop a technology-mediated teaching strategy. BMC Medical Education, London, v. 13, n. 1, p. 51, 2013.

SAMS, A.; BERGMANN, J. Flip your students' learning. Educational Leadership, Alexandria, v. 70, n.6, p.16-20, 2013.

SIEGLE, D. Technology: differentiating instruction by flipping the classroom. Gifted Child Today, Mobile, v. 37, n. 1, p. 51, 2014.

SILVA, Adelina. Da aula convencional para a aula invertida: ferramentas digitais para a aula de hoje. Série-Estudos, Campo Grande, MS, n. 39, p. 13-31, jan./jun. 2015.

STRAYER, J. How learning in an inverted classroom influences cooperation, innovation and task orientation. Learning Environments Research, v. 15, n. 2, p. $171,2012$.

WILLEY, K.; GARDNER, A. Flipping your classroom without flipping out. In: SEFI CONFERENCE, 41., 2013, Leuven, BE. Annals... . Leuven: KU LEuven, 2013 Disponível em: <

https://www.academia.edu/5153284/Flipping_your_classroom_without_flipping_out $>$.

WILSON, S. G. The flipped class: a method to address the challenges of an undergraduate statistics course. Teaching of Psychology, v. 40, n. 3, p. 193-199, 2013. 